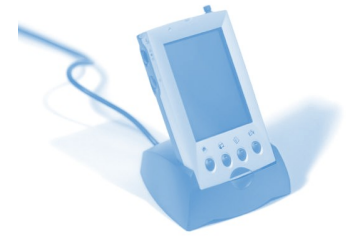

Timothy G Harrison and Dudley E Shallcross* Bristol ChemLabS School of Chemistry Bristol University BS8 1TS

*d.e.shallcross@bris.ac.uk

\section{Towards sustainable public engagement (outreach)}

\begin{abstract}
There are myriad benefits to science departments that have a public engagement in science portfolio in addition to any recruitment of new undergraduates. These benefits are discussed in this paper and include: improving congruence between A level and first year undergraduate courses, training in science communication and the breaking down of barriers between the public and universities. All activity requires investment of personnel and incurs a financial cost. Small scale activities may be able to absorb this cost, but ultimately as the portfolio grows this will become an increasing drain on resources. Bristol ChemLabS Outreach has, from the very start, set out to be fully sustainable financially and in terms of personnel. A very important component is the full support of the senior management team. In this paper we discuss how we have achieved this.

\section{Introduction}

There are many studies that demonstrate the importance of public engagement in science to schools and adults ${ }^{1,2,3,4}$ highlighting the importance of breaking down barriers between scientists and the public and promoting positive attitudes ${ }^{5}$ even increasing them $^{6}$. These activities can also impart the latest information accurately and not via a third party, allowing the public to ask questions. Such activities may have a positive impact on students' achievements in science ${ }^{7,8,9}$. The engagement with science can of course take a whole manner of forms, from one extreme, for example reading books to a full-blown hands-on event. It is also a good opportunity for scientists to become aware of general misconceptions in understanding that may be present and to refine their communication skills ${ }^{10}$. Recruitment is often cited as an important reason for conducting outreach (to schools at least) but there are many other benefits that far outweigh an increase in applications ${ }^{11,12,13,14}$.
\end{abstract}

the senior management

team... it was agreed that

Outreach to schools in

particular was something that a Chemistry

Department such as

Bristol's should be doing

to raise the profile of

Chemistry regardless of

its short and long term

impact on its own recruitment.

Outreach is at the core of the Bristol ChemLabS project (starting in 2005) and has carried on from a successful program that had been in place for five years previously. With the endorsement of the senior management team in the School of Chemistry at Bristol in 2000 it was agreed that outreach to schools in particular was something that a Chemistry Department such as Bristol's should be doing to raise the profile of chemistry regardless of its short and long term impact on its own recruitment. Indeed, in 2000 the School of Chemistry was already receiving as many applications from students in the local area that one would predict as a maximum based on A level grades and progression rates for $A$ level chemists to a degree in chemistry (about 10\%). During the previous five years a network of chemistry teachers had been built up called CHeMneT (<www.chemlabs.bris.ac.uk/outreach/chemnet/> April 2010) who advised the Schools' Liaison Officer on what events and activities to run and when to run them and, provided feedback on ways to improve these events. A key aspect of the outreach activity once the CETL was established was the appointment of a full-time School Teacher Fellow (STF) to work alongside the School's Liaison Officer (now called the Outreach Director). The role and impact of the STF are detailed in previous papers ${ }^{11,15}$. The impact of the STF has been enormous ${ }^{10,12,16,17,18,19}$ and the School of Chemistry now engages directly with over 30,000 people a year. The CETL funding is a finite sum of money for five years. How can we sustain such an activity beyond the life of the CETL? In the rest of this paper we outline some of the perceived barriers to outreach from both a University and School perspective and offer solutions to both, as well as suggesting how to make the operation sustainable in the long term, both in terms of personnel and finances, whether there is a full-time school teacher fellow or not. 


\section{Current barriers to outreach: a University perspective}

- A major barrier is the Senior Management Teams' (SMT) perception of the value of the activity. Many view such activities as an added extra and not part of the 'core business' of the department.

- Promotion is often cited as a reason for not engaging in outreach in many departments. Institutes' promotion and academic progression in general is linked to research activity and teaching; rarely is it linked specifically to public engagement. Therefore, not only is outreach a distraction from research and career progression; it is also often viewed as a distraction for postgraduates and postdoctoral researchers.

- The cost in terms of technical and secretarial staff as well as postgraduate and postdoctoral students can mount up and there is the risk of equipment breakages and general wear and tear. Raising funds for outreach activities can be difficult, especially raising small amounts of money.

- There is a latent fear that once the doors are opened to schools the department will be overwhelmed with requests from them.

- Not knowing what will go down well with schools is a barrier; it is terrible to put on an event that is inappropriate.

- To alleviate the previous problem it is advisable to make contact with school teachers, but this can be difficult. Phoning teachers is a lottery; several days can go by before one hits that perfect time when they are free to answer a call. E-mailing is also a lottery unless one has the relevant teacher's correct, frequently used, e-mail address. Contacting a head of science or headteacher either in writing, by phone or e-mail may appear to be a black hole as well. Once one contacts the teacher, finding a suitable event and pitching it at the right level takes time and effort.

- There appear to be no obvious benefits to 'local' outreach in terms of recruitment or research, apart from a little PR and perhaps a press cutting or two.

- Some believe there is no market for these interactions and therefore it is not worth engaging in them.

\section{Current barriers to outreach: a School perspective}

- Costs can be a barrier to many activities. These costs may include the cost of substitute (cover) teachers, travel and the charge for the event itself. Curiously, the cost of organising the event or, indeed, the 'overtime' costs of the teachers that may work outside of their normal hours are never calculated.

- The cramped curriculum demands may limit the outreach opportunity to one per school year per subject, if at all (unless it is for sports, drama or music).

- The difficulty of contacting a University. Many university websites are intractable. A teacher looking for outreach events or simply the name of the correct person to contact about such matters, may spend a long time trawling through a website and still come up empty handed. Such information should be made highly visible on the front page of any department website.

- Given the huge volume of paperwork such as health and safety (possibly including the requesting of risk assessments), contacting parents/carers, obtaining payments and permission slips, altering school meal numbers, hiring coaches or minibuses required for an event, whether on site or at a university or other venue, the organising teacher must be sure that this time and trouble would be well worth it.

- This leads directly to timing. The advertising period for an event is usually too short. Schools need to have plenty of time to organise the relevant paperwork and to communicate with families and other colleagues. Therefore, it is preferable to give a term's notice i.e. 6-8 weeks.

- Distances to travel can be a barrier. Some areas of the UK are not located conveniently close to a university that either has a chemistry (or relevant science) department or a department that is engaged in outreach activities.

- Headteacher's or Senior Leadership Team's (SLTs) value of such events may not be the same as the subject teacher or coordinator. This may be because they have no understanding of the educational value to students because they are not science trained themselves.

\section{Solutions to these barriers \\ University}

First it should be noted that the UK Higher Education Funding Councils, RCUK and the Wellcome Trust have established Beacons for Public Engagement in the last two years (see $<w w w . r c u k . a c . u k / s i s / b e a c o n s . h t m>, 2008)$. RCUK are keen that public engagement and research go hand in hand, so it may well be a more telling factor in obtaining research grants in the future, rather than the standard paragraph on dissemination that appears in most proposals today. Indeed, impact plans are now common requirements for RCUK grants and some element of public engagement is expected. In the USA, dissemination to the public is a non-negligible component for obtaining grants. Therefore, demonstration of outreach may become a necessary part of a research grant, where it will then most certainly become part of any SMT's agenda.

Second, we have noted in previous papers the many benefits of outreach activities to a science department (see previous references in this paper) in terms of establishing links with secondary school teachers and their input into teaching, particularly in first year courses. Teachers can advise on a wide range of issues, such as laboratory skills and the general congruence between A level and the first year of a degree ${ }^{20}$. The benefits to lecturers, postgraduates and postdoctoral researchers have also been discussed and will not be repeated in detail here. Leshner ${ }^{21}$ emphasises the very real need to train postgraduates and postdoctoral researchers in science communication.

The issue of promotion is a difficult one. At Bristol University and in other institutes a variety of career pathways has been established that recognises the importance of research, teaching and public engagement. However, the authors have found themselves invited to a variety of countries to present outreach activities and to train others to do the same. On many occasions these outreach activities are based at local Universities and in every instance we have been invited to give research lectures. Following on from these lectures we have been invited to present plenary or keynote lectures at conferences. In several instances important research 
collaborations have been established on the back of public engagement, an unforeseen and positive impact of public engagement. In the UK it has brought us into contact with a completely different set of academics and here too synergies in research have emerged (in particular cross disciplinary) that would never have occurred through regular research links. Hence, in our experience public engagement has enhanced research activity in ways that could not have been envisaged and that alone can feed back into promotion whatever progression scheme is operated by that institute. In our particular area of research, atmospheric science, working with schools to obtain measurement data has been a particular bonus for both sides.

We will cover the issue of cost for both parties under sustainability. In our experience school teachers are overwhelmed themselves and very wary of bothering academics. Therefore, in the ten years that we have been running an outreach program we have never been overwhelmed in the way many colleagues fear.

It can be hard establishing links with secondary school teachers but this is the key to a successful school outreach program.

Working in partnership with school teachers to develop activities is clearly the most sensible way of avoiding a poor engagement activity. Our advice would be to not try telephoning teachers at school. The best ways to establish links are usually face to face. Here are some suggestions:

- Present yourself at local and national teachers' conferences, for example, local ASE events.

- Link up with your local Science Learning Centre and either ask for a message to be posted to their portal, which will automatically be sent to their school teacher network, or carry out an event at the SLC.

- Science advisors for local authorities are a useful source of information as are local SETPoints, now called STEMPoints.

- Closer to home one can ask all members of your department or faculty to find out the names and contact details of their children's science teachers. Your departmental admission officer will of course have information on schools in the region, but may not have named teachers. Or you can contact your institute's widening participation officer or Undergraduate Ambassador Scheme co-ordinator ${ }^{22}$.

- You can try a cold letter drop but don't expect a high hit rate and, particularly for independent schools, it may be worth searching websites.
Once you have established a few links, either visit the teachers or invite them to your institute for a discussion on possible events and their timings. Make this meeting after school hours and if possible reimburse travel costs. It would then be sensible to establish a teaching advisory board (Shallcross et al., 2010) that would meet 2 times a year, involving these teachers and a few academics, to plan outreach activities for the next 3-6 months and also to discuss undergraduate teaching modules in the department with these teachers.

If the Bristol ChemLabS experience is a general one, having established a local network of teachers and outreach activities, it will not be long before outreach activity spreads well beyond your local region ${ }^{17}$, particularly if you establish links with the Science Learning Centre networks. The difficulty in establishing contacts with secondary schools may be perceived as an indicator that there is no market: nothing could be further from the truth.

\section{UK Schools}

With the freeing up of curriculum time in Key Stage 3 (KS3) and the requirement at KS4 and post 16 to incorporate 'How Science Works' in the latest science GCSE and A levels there is a very strong driver to override the excuse of a cramped curriculum, even with the 'rarely cover' policy. This policy was put in place in 2009 to ensure that teachers 'rarely cover' the classes of colleagues who are absent However, if the activity has been booked in advance, as suggested, this should include provision for teacher cover and will not be affected by this new policy. It should be noted that this policy was not designed to prevent outside activities but to ensure that teachers are not overloaded with additional teaching; therefore the need for good planning and preparation is essential.

In today's litigious society, properly completed paperwork cannot be avoided. All this takes time and that is why at least a term's notice is required. Risk assessments should be readily available from the University to aid the teacher. It should be normal practice to work through risk assessments with the teacher. This will help to shape the activity.

Distances are a major hindrance to some engagement activities. If the distance is too far for the students to come to the HEI for a day's event it is possible to (a) take a version of the event to the school or (b) provide several overnight events e.g. a summer school or chemistry camp that individual students can access. Taking outreach to the school is a little more limiting in that there is less of a 'wow' factor than a student entering a science department and being able to use the undergraduate teaching labs or sit in a lecture theatre. 
Preferably, this engagement uses some postgraduate chemists, not just the academics. The distances can of course be shortened for many if more university science departments provide more outreach opportunities. Experience at Bristol tells us that schools will travel in excess of 2 hours in each direction for the opportunity to engage.

The reluctance of some Headteachers to allow outreach is also a difficult problem. However, if the activities at neighbouring schools are a success then that is the best recommendation. If time permits, discussion with the Headteacher can be a very positive action.

\section{Sustainability}

It goes without saying that sustainability involves both people and finances. The key message is do not overload staff or students. Postgraduate students are a vital part of our Outreach Portfolio, particularly in laboratory practical sessions at the University and hands-on science workshops. These students receive training from our local STEMPoint and become Science Ambassadors. We provide additional specific training for the various activities and each Ambassador is paid for all the outreach they do for us. Although there is an initial investment in time, the energy, enthusiasm and new ideas that these students provide, as well as being excellent role models means that academics and technicians need not be doing everything. Schools in particular would prefer to have one event done well than five mediocre ones, and so it is vital to ensure that activity does not outstrip resource. The School of Chemistry appointed a Schools' Liaison Officer in 2000 and that was their administrative job. They did not have additional jobs to do; full support from the SMT is essential.

There will of course be major projects from time to time funding outreach such as the Royal Society of Chemistry led Chemistry the Next Generation (C:NTG; <www.rsc.org/pdf/ education/aimhigher.pdf> April 2010) and Chemistry for our Future (CFOF) ${ }^{23}$, both projects being funded by HEFCE. However, in both cases not all regions in England were supported (including Bristol) with funding and in any case what happens when this money runs out? Does all the outreach come to a halt? There are a number of funders one can apply to e.g. Wellcome Trust, AstraZeneca Science Teaching Trust, local sections of the Royal Society of Chemistry, local sections of the Institute of Physics, and other learned societies. It may also be possible to obtain seed corn funding from within the University (even in the present climate). There are EU calls that may be appropriate for groups that have already established a portfolio of activities.
Outreach provision costs money and time and under full economic costs it is a lot of money. There is no easy solution; it takes time to establish a broad portfolio of income streams. It is instructive to carry out a full economic cost for each activity. You may not charge that amount but you will know what a break-even cost is.

We all know that grant applications take time to write and are not always successful, so how can we make the activity sustainable in the long term? Should charges be made to schools in the first place? It is our standard working practice to charge schools at least a token charge for an event. This has significantly reduced the 'no show' or last minute cancellations. Headteachers, in circumstances where there is a high staff absence would prefer to cancel a free event whereas they think twice about cancelling an event that incurs costs. There is also a higher expectation that an event that costs money has more value than one that is 'free' despite the costs to the provider being the same. Even with a reserve list of schools/students wishing to take part in an activity cancellations usually mean that resources are wasted. Schools pay for a variety of activities, or charge the parents, particularly in areas such as music and drama, so why not science? Having established the quality of the event, charging is possible and leads to financial sustainability, independent of grants.

For schools, there are funding streams for sections of the school community using a crude assessment based on individuals or whole school type and performance that can aid them with internal costs, such as teachers cover. Other sources of funding do exist for schools that will help them to cover the costs of the activity provided. We have constructed a list of potential funders to which schools can apply to obtain funds to engage with university science departments (see <www.chemlabs.bris.ac.uk/outreach/ resources/Sources_of_funding.pdf >; April 2010).

There are a range of funds that the school itself can apply for, such as the Royal Society Partnership grant scheme, and we have found considerable success aiding schools in applications to these and other groups. Grants are also available from within the education authorities and child services and from within the schools themselves (gifted and talented, enrichment). Once again, working with schools on developing bids for funding can be extremely successful. Since charging for events we have seen the number of applicants increase not decrease and this has been maintained even in the recent economic downturn. Once a portfolio has been established then one can think about the international dimension and running summer schools for students from overseas. 
In the School of Chemistry at Bristol University all RCUK grant applicants are asked to add some of the STFs time onto their grant (up to $5 \%$ ), just as you would add technician time or computer support time. In this way new grants are supported by public engagement activities and they in turn support on-going outreach. Following extensive discussions with our alumni office, they started to discuss sponsoring our activities with alumni. We now receive donations from alumni specifically to support outreach and this is a growing component of our funding stream. It is great to have alumni come back to the department and want to support the work that goes on to promote science. We have also been fortunate to develop commercial software that also brings in an income stream to support outreach ${ }^{12}$.

The general public are very interested in science and we have found that taster days are very popular (garden chemistry, chemistry of food, etc.) and can fill in slots when teaching laboratories are not being used. They can be fun to devise and once trialled and modified are a great way develop relations with the local community. It has been our experience that having a range of new people coming into the department has had unforeseen benefits. Many new groups, such as local interest groups now engage with us. Some have led to additional funding streams, some to useful contacts for new projects but, above all, we have engaged with some enthusiastic and interesting people.

Currently, grants make up less than $20 \%$ of our budget for outreach, with the rest coming from direct income from events $(\sim 60 \%)$, alumni $(\sim 10 \%)$ and software sales $(\sim 10 \%)$. Our aim in the next two years is to be independent of grants and to use them to stimulate new project areas only. It is perfectly possible to operate a sustainable outreach activity by charging for events, without driving schools and the general public away. We do have an obligation to communicate with the public and so some activities will of course be free of charge, but a balanced portfolio will include these.

\section{Summary}

There are many barriers to engaging in outreach to schools and the public and there is a very real cost in terms of resources and people's time. However, it is perfectly possible to overcome these barriers and to establish a sustainable activity. The most important points are to have a supportive senior management team within your department, to set realistic targets for events, to cost all activities so that you know how much each element costs, and to not be afraid to levy a charge for activities. The long term benefits of a successful public engagement programme are substantial for teaching and research, for training of postgraduates, for raising the profile of the department and institute and bringing a department into contact with a new set of people. In many cases these new people have themselves been extremely beneficial to the department in terms of advice and support.

\section{Acknowledgments}

We thank Bristol ChemLabS for support and DES thanks the Higher Education Academy (HEA) for a National Teaching Fellowship. If anyone would like us to give a presentation on what we have done, its benefits and how to achieve sustainability, please contact Dudley Shallcross or Tim Harrison. We would be delighted to help if at all possible.

\section{References}

1. Hutton, N. (1996), Interactions Between the Formal UK School Science Curriculum and the Public Understanding of Science, Public Understanding of Science, 5, 41-53.

2. Smith, H.A. (2003), Public Attitudes towards Space Science, Space Science Reviews, 105, 493-505.

3. Stuckey, H.T. and Sattler, M.L. (2003), Air quality in the $21^{\text {st }}$ Century: Community Outreach in North Central Texas, Environment International, 29, 341-346.

4. Greenler, R.G., Lasca, N.P., Brooks, A.S. and Shaw, C.F (1992) The Science Bag at the University of WisconsinMilwaukee: A Successful Forum for Science Outreach, American Journal of Physics, 61 (4), 326-329.

5. Gibson, H.L. and Chase, C. (2002) Longitudinal Impact of an Inquiry-Based Science Program on Middle School Students' Attitudes toward Science, Science Education, 86 (5), 693-705.

6. Schmidt, B. M. and Nixon, R. M. (1996), Improving Girls' Attitudes Towards Science, Public Understanding of Science, 5, 255-268.

7. Hofstein, A. and Lunetta, V.N. (1982), The Role of the Laboratory in Science Teaching: Neglected Aspects of Research, Review of Educational Research, 52, 201-217.

8. Hofstein, A., Maoz, N. and Rishpon, M. (1990), Attitudes towards School Science: A Comparison of Participants and Nonparticipants in Extracurricular Science Activities', School Science and Mathematics, 90 (1), 13-22.

9. Hofstein, A. (2004), The Laboratory in Chemistry Education: Thirty Years of Experience with Developments, Implementation and Research, Chemistry Education: Research and Practice, 5 (3), 247-264.

10. Shallcross, D.E. and Harrison, T.G. (2007a), Why bother taking University led Chemistry Outreach into Primary Schools? Bristol ChemLabS experience, New Directions, 3, 41-44.

11. Shallcross, D.E. and Harrison, T.G. (2007b), The impact of School Teacher Fellows on teaching and assessment at tertiary level, New Directions, 3, 77-78.

12. Harrison, T.G., Shallcross, D.E., Heslop, W.J., Eastman, J.R and Baldwin, A. (2009a) Transferring best practice from undergraduate practical teaching to secondary schools: The Dynamic Laboratory Manual, Acta Didactica Napocensia, 2 (1), 1-8.

13. Tuah, J., Harrison, T.G. and Shallcross, D.E. (2009), The advantages perceived by schoolteachers in engaging their students in university-based chemistry outreach activities, Acta Didactica Napocensia, 2 (3), 31-44.

14. Harrison, T. G. and Shallcross, D. E. (2010), What should be Expected of Successful Engagement between Schools, Colleges and Universities?, School Science Review, 91 (35), 97-102.

15. Shallcross, D.E. and Harrison, T.G. (2007c), A Secondary School Teacher Fellow within a University Chemistry Department: The answer to problems of recruitment and transition from secondary school to University and subsequent retention?, Chemistry Education Research and Practice, 8,101-104.

16. Shallcross, D.E. and Harrison, T.G. (2008) Practical demonstrations to augment climate change lessons, Science in School, 10, 46-50. <www.scienceinschool.org/2008/issue10/climate>

17. Harrison, T. G., Hughes, L. and Shallcross, D. E. (2009b), Jersey Schools Science Week: An Outreach Case Study, New Directions, 4, 30-33. 
18. Shaw, A.J., Harrison, T.G., Shallcross, D.E. and Medley, M.I. (2009), Chemistry Inreach: Engaging with University Employees' Children within a Chemistry Department, Acta Didactica Napocensia, 2 (4), 107-112.

19. Shaw, A.J., Harrison, T.G., Croker, S.J., Medley., M.I., Shallcross, K.L., Williams, S.J. and Shallcross, D.E. (2010), University-School partnerships: Polymer Chemistry days run at a University for 14-15 year olds and their impact on attitudes to Science, Acta Didactica Napocensia, 3 (1), 19-26.

20. Shallcross, D.E. and Harrison, T.G. Norman, N.C. and Wyatt, P.J. (2010), The importance of advisory boards in undergraduate chemistry teaching, Romanian Journal of Education, 1 (1), 61-66.

21. Leshner, A.I. (2007), Outreach Training Needed, Science, 315, (5809) 161, DOI: 10.1126/science.1138712.

22. Harrison, T.G., Smith, D. M. and Shallcross, D. E. (2009c), Final year School Projects: The Bristol ChemLabS Use of the Undergraduate Ambassador Scheme, Acta Didactica Napocensia, 2 (2), 35-40.

23. Tunney, J. (2009), A legacy for chemistry education, New Directions, 5, 7-11.

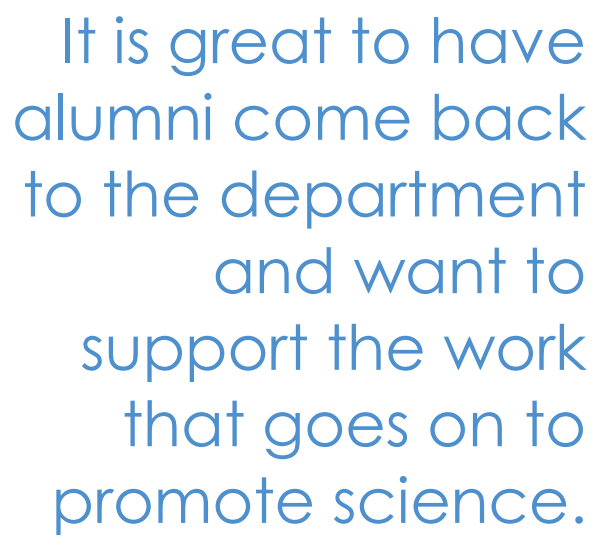

